\title{
THE MOTION OF THE SWARM IN PROTEUS MIRABILIS
}

\author{
K. A. BISSET \\ Department of Bacteriology, University of Birmingham
}

Plates I AND II

Most recent work on the swarming of Proteus has been directed to the problems of metabolism; this is discussed by Grabow (1972). It seems tacitly to be assumed that the swarmers move purposefully outwards to gain some advantage or overcome some disadvantage. Studies by direct phase-contrast microscopy have led me to the conclusion that the motion is random, and that the main source of energy in the spreading of the swarm is its own growth.

\section{MATERIALS AND METHODS}

Two strains of Proteus mirabilis, isolated and identified by Mr J. Wolstenholme in this Department, were grown on agar plates (BBL Trypticase Soy) that had been partially dried by being left, closed, for $18 \mathrm{hr}$ at $25^{\circ} \mathrm{C}$. Cultures were incubated at $25^{\circ} \mathrm{C}$ or $37^{\circ} \mathrm{C}$.

Time-lapse photomicrographs at intervals of 10 and $20 \mathrm{~s}$ were made, with the $\times 10$ and $\times 40$ lenses of a Vickers phase-contrast microscope, of surface growth on the uncovered plate, which thus was not constrained or interfered with in any way so long as it was not permitted to dry unduly. This could, in fact, be prevented by melting a hole in the cover of a plastic petri dish, through which the lens could pass; but such was the speed of the processes described that it was seldom necessary.

\section{RESULTS}

After $3-4 \mathrm{hr}$ at $37^{\circ} \mathrm{C}$, or $5-6 \mathrm{hr}$ at $25^{\circ} \mathrm{C}$, a thin film of growth extended 5-10 $\mathrm{mm}$ from the point of inoculation. Under the phase-contrast microscope this was seen to consist of a mesh of strands, each 5-10 bacterial filaments in width, down to single filaments at the edge of the swarm (fig. 1). There was some sluggish movement of single organisms or small groups at the edges of the swarm - not necessarily outwards, but indifferently, in any direction-but the main movement consisted of compact bodies of a dozen to a hundred swarmers that passed along the meshes exactly as if the latter were roads or railways; these bodies also moved indifferently in any direction, but spread outwards as an effect of this general movement.

As the swarm developed, the growth of the constituent bacteria filled up the spaces, so that there was a continuous layer of growth, usually one or two, and rarely more than three to four bacteria in thickness. The structure was notably filamentous, and resembled a Medusa-head colony, except that all parts were in continuous motion along the direction of the coils (fig. 2). This movement was very rapid and active, but was not in the direction of expansion of the swarm: in fact, at the edges it was mainly at right-angles to this. As

Received 26 May 1972; accepted 13 June 1972. 


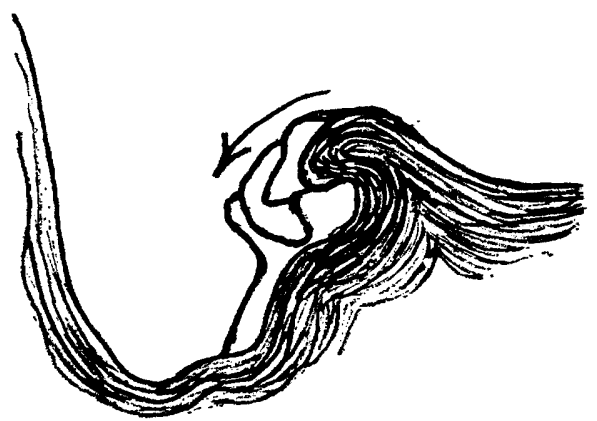

FIG. 7.

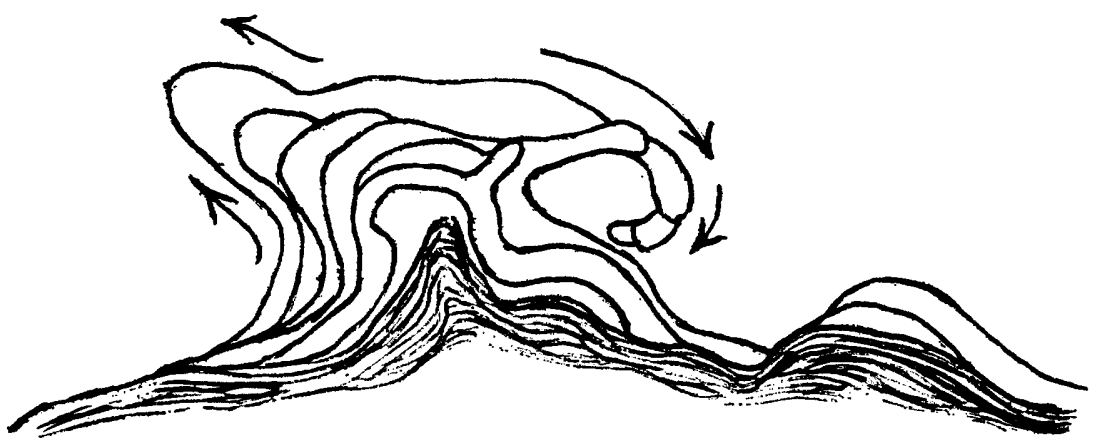

FIG. 8.

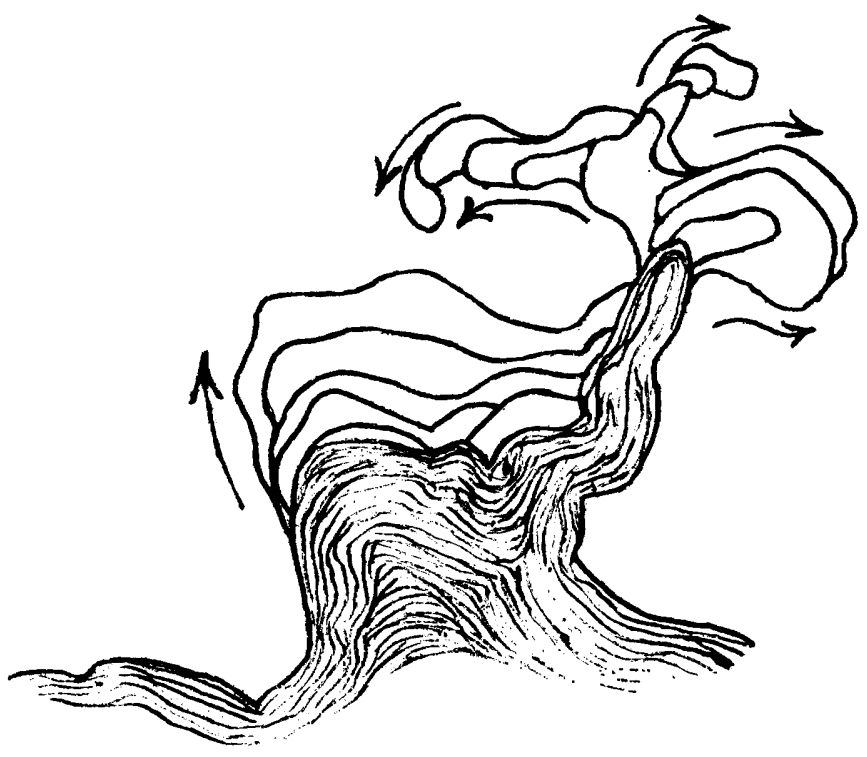

FIG. 9.

Figs. 7-9.-Tracings from time-lapse photomicrographs of the edge of a mature swarm $(12 \mathrm{hr}$ at $37^{\circ} \mathrm{C}$ ) showing the growth of projections. These grow outwards only for a limited period and then tend to curve back towards the main body. The closely hatched portion represents the swarm at the beginning of the observations; the open lines are drawn at intervals representing intervals of $10 \mathrm{~s}$. The arrows show the direction of the swarming movement. $\times 200$. 


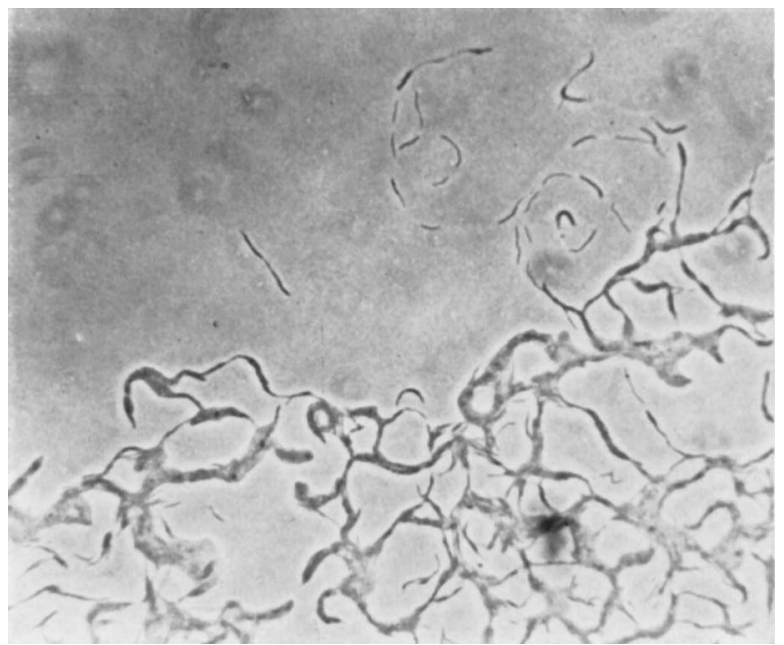

FIG. 1.-Edge of a young swarm $\left(4 \mathrm{hr}\right.$ at $\left.37^{\circ} \mathrm{C}\right)$ showing a mesh of bacterial filaments, preceded by small groups and single bacteria, from which the mesh is developed. Larger bodies of bacteria migrate in various directions along the more developed strands. Phase contrast, in situ. $\times 100$.

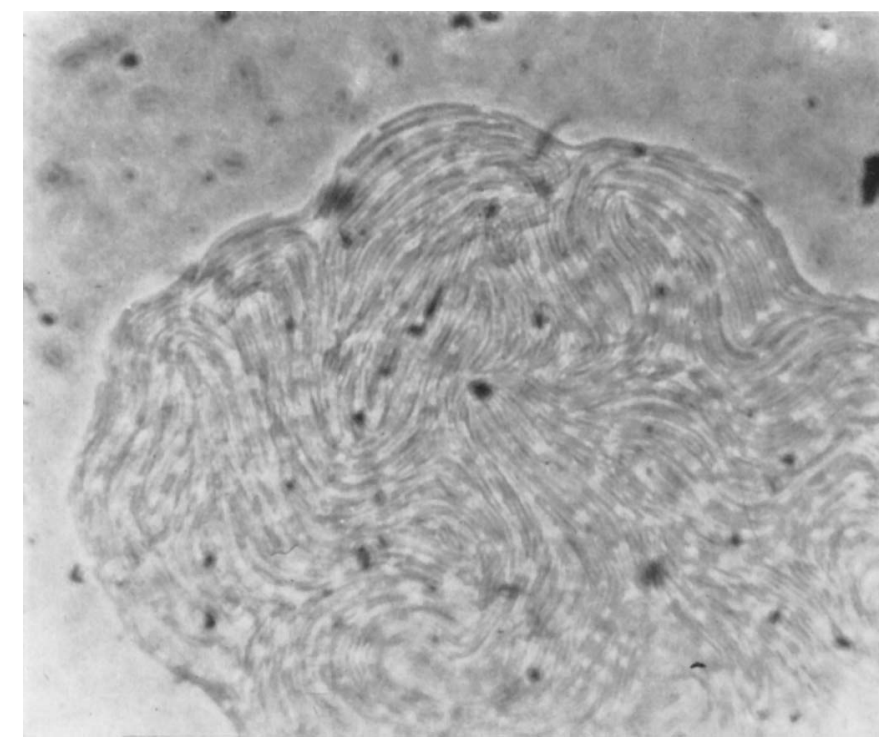

Fig. 2.-Lobe of a mature swarm $\left(12 \mathrm{hr}\right.$ at $\left.37^{\circ} \mathrm{C}\right)$ advancing at $c .1 \mu \mathrm{m}$ per s, in the direction of the top of the page. All parts are in active motion along the lines of growth, and thus at right-angles to the direction of advance of the swarm at the top edge. The resemblance to a Medusa-head colony is most marked. Phase contrast, in situ. $\times 400$. 


\section{MOTION OF THE SWARM IN PROTEUS MIRABILIS}

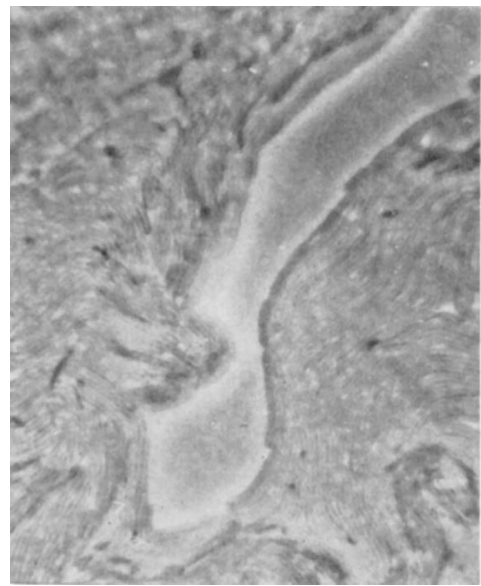

FIG. 3.

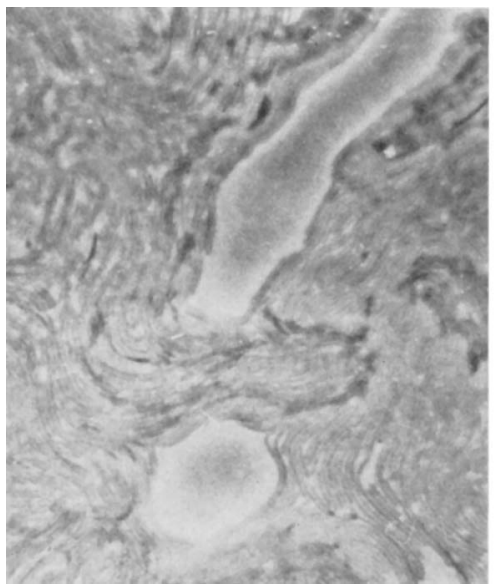

FIG. 5.

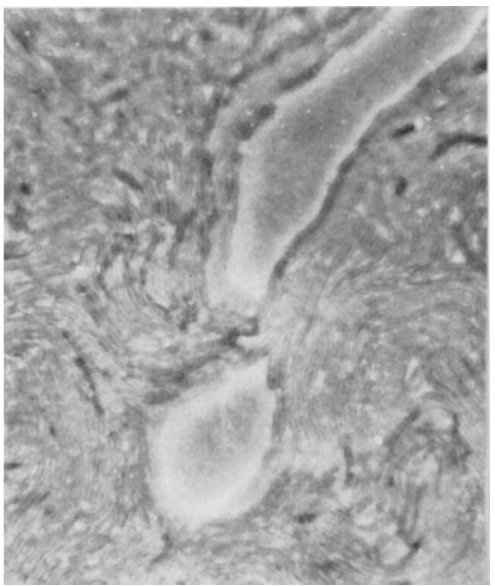

FIG. 4.

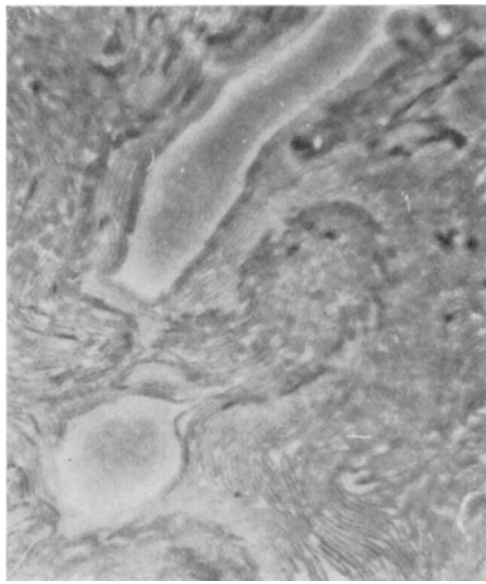

Fig. 6.

Figs. 3-6.-Movement within a mature swarm $\left(12 \mathrm{hr}\right.$ at $\left.37^{\circ} \mathrm{C}\right)$. The advancing edge of the swarm is towards the top of the page. A channel between two lobes of the swarm (compare fig. 2) is being bridged by a body of several hundred bacteria, migrating from left to right, and at right-angles to the direction of the swarm, in this area. In fig. 3, a projection appears on the left-hand side of the channel; in fig. 4, the channel is bridged; in fig. 5, the mass continues to cross, and forces its way into the right-hand side of the channel; in fig. 6 , the movement continues, and the moving mass begins to separate from its origin on the left-hand side. Time-lapse photomicrographs, at intervals of $20 \mathrm{~s}$, phase contrast, in situ. $\times 400$. 
the swarm expanded, the moving swarmers also advanced sideways to produce this general movement. The masses of swarmers, now sometimes comprising several hundred members, moved about within the swarm (figs. 3-6) in the same general way as previously, but with the same result of extending the area of the swarm. Projections formed, but these seldom advanced in a consistent manner; rather they tended to coil around and become readsorbed with the main body of the swarm (figs. 7-9.)

\section{DisCUSSION}

These observations tend to confirm that of Hughes (1957), who showed that the swarmers move along lines of existing growth (the meshes, here described), and of Morrison and Scott (1966), who described masses, which they called " rafts" of swarmers, moving out from the edges of the swarm. This certainly occurs, but it is merely one aspect of the movement of masses within the swarm.

When the culture has grown sufficiently to fill in the space covered by the swarm, subsequent expansion closely resembles an accelerated version of the growth of a Medusa-head colony (Bisset, 1939). The motility of the swarmers serves a dual purpose; first, to permit quantities of bacteria to be transported outwards to the spreading edge-always, however, as a by-product of their random motion within the swarm; second, to act as a "lubricant", so that the masses of bacteria can move outwards under the pressure of those nearer the centre.

It is worthy of notice that the swarm of Proteus resembles the Medusa-head colony in a second respect, namely that many of the observations purporting to explain its mechanics have been made upon bacteria constrained between slide and coverslip, under quite a different set of physical conditions from the surface of an agar plate (Bisset).

\section{SUMMARY}

Observations by phase-contrast microscopy upon the swarm of Proteus mirabilis lead to the conclusion that its development is in two stages; at first, as an open mesh of bacterial strands, along which bodies of swarmers migrate in any direction; later, when these meshes have filled up to give a continuous film of bacteria, expansion continues by the growth of the whole body, in the manner of a Medusa-head colony. All parts are in motion, and masses of several hundred units move about within the swarm. The total effect is a general expansion, but the main motion of swarmers at the edges is at rightangles to the direction in which the swarm is extending.

\section{REFERENCES}

Bisset, K. A. 1939. The mode of growth of bacterial colonies. J. Path. Bact., 48, 427.

Grabow, W. O. K. 1972. Growth-inhibiting metabolites of Proteus mirabilis. J. Med. Microbiol., 5, 191.

Hughes, W. H. 1957. A reconsideration of the swarming of Proteus vulgaris. J. Gen. Microbiol., 17, 49.

Morrison, R. B., AND ScotT, ANN 1966. Swarming of Proteus-a solution to an old problem? Nature, Lond., 211, 255. 